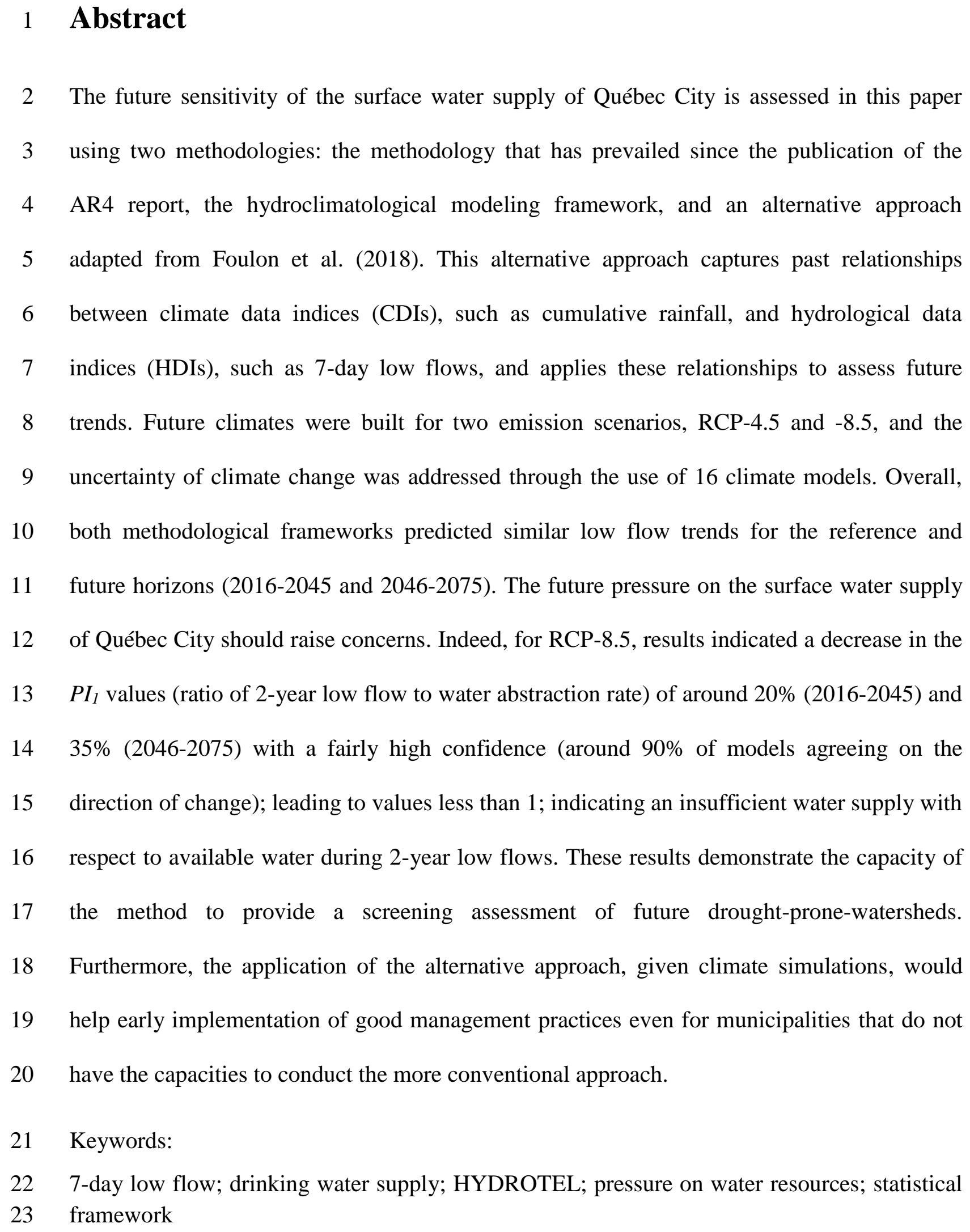

2 The future sensitivity of the surface water supply of Québec City is assessed in this paper 3 using two methodologies: the methodology that has prevailed since the publication of the 4 AR4 report, the hydroclimatological modeling framework, and an alternative approach 5 adapted from Foulon et al. (2018). This alternative approach captures past relationships 6 between climate data indices (CDIs), such as cumulative rainfall, and hydrological data 7 indices (HDIs), such as 7-day low flows, and applies these relationships to assess future 8 trends. Future climates were built for two emission scenarios, RCP-4.5 and -8.5 , and the 9 uncertainty of climate change was addressed through the use of 16 climate models. Overall, 10 both methodological frameworks predicted similar low flow trends for the reference and 11 future horizons (2016-2045 and 2046-2075). The future pressure on the surface water supply 12 of Québec City should raise concerns. Indeed, for RCP-8.5, results indicated a decrease in the $13 P I_{l}$ values (ratio of 2-year low flow to water abstraction rate) of around $20 \%$ (2016-2045) and $1435 \%(2046-2075)$ with a fairly high confidence (around 90\% of models agreeing on the 15 direction of change); leading to values less than 1; indicating an insufficient water supply with 16 respect to available water during 2-year low flows. These results demonstrate the capacity of 17 the method to provide a screening assessment of future drought-prone-watersheds. 18 Furthermore, the application of the alternative approach, given climate simulations, would 19 help early implementation of good management practices even for municipalities that do not 20 have the capacities to conduct the more conventional approach.

21 Keywords:

22 7-day low flow; drinking water supply; HYDROTEL; pressure on water resources; statistical 23 framework 


\section{Introduction}

Rivers and lakes supply around 40\% of Québec's population (MDDELCC 2016). According to CEHQ (2015), summer $\mathrm{Q}_{2-7}$ and $\mathrm{Q}_{10-7}$ (annual minimum of 7-day flow with return periods of two and ten years) are projected to decrease (ranked as highly probable) by 2050 for all Southern Québec (between $-10 \%$ to $-45 \%$ RCP-4.5 and up to $-50 \%$ for RCP-8.5), which is home to $95 \%$ of the population (Institut de la statistique du Québec 2015). This obviously would lead to local water stress conditions. In Québec, summers 2001, 2002, 2005, 2010 and 2012 have all been characterized by extremely low flows; leading to drinking water stresses and, in one instance, requiring mandated excavation works on the Mille Îles River to maintain flows above a specific threshold $\left(25 \mathrm{~m}^{3} / \mathrm{s}\right)$ (COBAMIL 2014) to ensure adequate drinking water supply (summer low flow reaching $11.8 \mathrm{~m}^{3} / \mathrm{s}$ in 2010). The Yamaska River water supply system of St. Hyacinthe has had to deal with critical water availability problems one year out of five (based on the 1971-2000 period). For the 2041-2070 time period, Côté et al. (2013) indicated that in all likelihood it would be the case one year out of two. Given these multiple problematic situations; current and historical sensitivities of recreational activities and water supply to low flows (Bérubé 2007; Nantel 2006), and the projected downward trends for low flows in Southern Québec (CEHQ 2015), there is a need to assess whether these sensitivities will locally increase in the future.

Smakhtin (2001) demonstrated that a clear understanding of low flow hydrology can help resource specialists manage, for example, municipal water supply, river navigation, and even wildlife conservation. Since publication of the IPCC AR4 report (IPCC 2007), several impact studies have been carried out throughout the world (Kundzewicz et al. 2007; Todd et al. 2011) following a quasi-standard methodology (Blöschl and Montanari 2010; Todd et al. 2011), the hydroclimatological modeling framework. This approach combines the use of a hydrological model with bias-corrected output of climate simulations, but it remains challenging and 
cannot be readily applied by any water organization because of the required expertise and 50 underlying uncertainties. The latter uncertainties are associated with: (i) the existence of many 51 local optima (equifinality) arising during the calibration of a hydrological model (Beven 


\section{Material \& Methods}

\subsection{Case study} that is June to the end of November.

This section introduces the case study for which future water sensitivity to low flows is assessed by computing future summer ${ }_{7 d} Q_{\min }$ (annual minimum of the 7 consecutive-day average flow). Then, Québec main water treatment plant sensitivity to low flows is computed as a pressure index (PI) derived from the $\mathrm{Q}_{2-7}$.

Château d'Eau is Québec City's main water intake and provides drinking water to more than 237,000 people (Brodeur et al. 2012) out of the 350,000 living in the associated watershed. The intake is $11 \mathrm{~km}$ downstream of Lake Saint-Charles and is supplied by the $360-\mathrm{km}^{2}$ St. Charles watershed (see Fig. 1). At the intake, the mean flow is $1.7 \mathrm{~m}^{3} / \mathrm{s}$, according to data provided by Québec City for the period 2006-2017 at a 3-hour time step.

Fig. 1 Location of the study watershed and the modeled subwatersheds in the province of Québec. Green, blue, yellow, and red illustrate the Nelson, Des Hurons, Jaune and St. Charles subwatersheds, respectively

Low flows play an important role for the Château d'Eau water intake. In 2003, enough water was kept into the intake by dredging Lake Saint-Charles (Salou 2009). A year earlier and again in 2010, an old pumping station from the nearby Jacques Cartier River had to be turned back on to ensure enough water was available (Brodeur et al. 2012). The St. Charles River minimum flows are regulated. They must be maintained above ecological minimum flow limits of $0.6 \mathrm{~m}^{3} / \mathrm{s}$ at least. But, these conditions are not always met. In fact in 2012-2016, recorded flows at the hydrometric station downstream of the water intake were smaller for 116 days (10.9\% of regulated days) (Ouranos 2016). Given that the lowest flows occur during the summer for the St. Charles River, this paper focused on the assessment of summer ${ }_{7 d} Q_{\min }$; 


\subsection{Climate simulations}

97 To investigate the effect of global warming on low flows, 32 simulations from 16 different 98 GCMs, presented in Table 1, were used. These simulations were retrieved from the climate 99 ensemble (cQ)2 produced by Ouranos from CMIP5 simulations for RCP-4.5 (Thomson et al. 100 2011) and RCP-8.5 (Riahi et al. 2011).

101 Table 1 List of the selected Global Climate Models

\begin{tabular}{cccc}
\hline BCC-CSM1-1-m & CMCC-CMS & IPSL-CM5A-MR & MPI-ESM-LR \\
BCC-CSM1-1 & GFDL-CM3 & IPSL-CM5B-LR & MPI-ESM-MR \\
CanESM2 & GFDL-ESM2G & INMCM4 & MRI-CGCM3 \\
CMCC-CM & GFDL-ESM2M & MIROC5 & NorESM1-M \\
\hline
\end{tabular}

103 Simulation data were corrected using the daily translation method (Mpelasoka and Chiew 104 2009). The temperature correction is additive while the correction for precipitation is 105 multiplicative. This post-processing method assumes the biases to be of equal magnitude in 106 the future and reference periods (Huard 2010). The reference period 1961-2000 and observed 107 precipitation data came from a $10-\mathrm{km}$ grid covering southern Canada, that is south of $60^{\circ} \mathrm{N}$ 108 (Hutchinson et al. 2009), averaged on the GCM grid before application of the bias correction 109 methodology.

\section{2.3. Hydroclimatological modeling: conventional approach}

111 This conventional approach is based on the correction of climate simulations and the use of a 112 calibrated/validated hydrological model. The latter is then used to generate the series of future 113 summer ${ }_{7 d} Q_{\min }$ at the hydrometric station closest to the inlet of Château d'Eau.

\section{2.3.1. The hydrological model HYDROTEL}

115 HYDROTEL is a process-based, continuous, semi-distributed hydrological model (Fortin et 116 al. 2001; Turcotte et al. 2007; Turcotte et al. 2003) that is currently used for inflow 
117 forecasting by Hydro-Quebec. It is based on the spatial segmentation of a watershed into

relatively homogeneous hydrological units (RHHUs, elementary subwatersheds or hillslopes as desired) and interconnected river segments (RSs) draining the aforementioned units. The model is composed of seven computational modules, which run in successive steps. Readers are referred to Fortin et al. (2001) and Turcotte et al. (2007) for more details about HYDROTEL.

123 Fig. 1 presents the subwatersheds that were modeled in HYDROTEL. The Jaune, Nelson, and 124 St. Charles supply the intake while the Des Hurons River discharges into Lake Saint-Charles. 125 Since the grey drainage area does not supply the drinking water intake, it was not modeled. 126 The watershed was divided into 1505 RHHUs (i.e., hillslopes) with mean areas of 36.8 ha and 127668 river segments with mean lengths of $968 \mathrm{~m}$ (excluding lakes), defining four regions of 128 interest for parametrization. These regions were used to define local parameter sets of 129 consistent values for model calibration. The discretization provided a good representation of 130 the river network and of the spatial heterogeneity of the landcover while allowing for a 131 reasonable computational time. Four specific river segments and gauging stations (St. Charles 132 River + one per each tributary) introduced in Fig. 1 were selected for calibration and 133 validation.

\section{2.3.2. Calibration/validation and parameter sets generation}

135 As proposed by Foulon and Rousseau (2018), out of 18 key parameters for HYDROTEL, 12 136 were actually adjusted to account for knowledge built though prior uses of the model. The 137 remaining parameters were fixed according to: (i) a regionalization study(Turcotte et al. 2007), (ii) results from the application of a global calibration strategy (Ricard et al. 2013) 139 used in CEHQ (2015), and (iii) previous manual calibration exercises.

140 Calibration/validation were performed sequentially over five-year periods (not including a 1141 year spin-up period used to minimize initialization errors) according to available observed 
142 climate data provided by CEHQ for the 1985-2016 period. First, the upstream subwatersheds

(Nelson, Des Hurons, and Jaune) were calibrated/validated, then the St. Charles subwatershed using the calibrated flows of the upstream watersheds as inflows. Later on in this paper, this sequential exercise is referred to as one (1) calibration. The calibration/validation periods extended over hydrological years defined from November $1^{\text {st }}$ to October $31^{\text {st }}$ of the following calendar year.

HYDROTEL was calibrated automatically using a global optimization algorithm, dynamically dimensioned search (DDS) developed by Tolson and Shoemaker (2007). It allows systematic impartial and calibration based on the maximization of the Nash-log-7-day objective function (OF or pseudolikelihood function in statistical terms), which is the Nash152 Sutcliffe efficiency (NSE) calculated on log transformed 7-consecutive-day average flows as 153 follows:

$154 \quad$ Nash $-\log =1-\frac{\sum_{t=1}^{T}\left(\log Q_{m}^{t}-\log Q_{o}^{t}\right)^{2}}{\sum_{t=1}^{T}\left(\log Q_{o}^{t}-\overline{\log Q_{o}}\right)^{2}}$

155 where $Q_{o}^{t}$ is the 7-day mean of observed flows a time $t$ (using the 7 days prior to time $t$ ), $Q_{m}^{t}$ is 156 the 7-day mean of modeled flow at time $t$, and $Q_{0}$ is the 7-day observed flow. 157 average over the whole series.

158 DDS was executed following the guidelines and implementation steps provided in Tolson and 159 Shoemaker (2008) to quantify prediction uncertainty resulting from the acceptance of the 160 equifinality concept. Readers are referred to Online Resource 1 to get the details of the 161 calibration procedure used to generate the equifinal sets of parameters (behavioral).

\subsubsection{Computation of the hydrological data indices - HDIs}

163 Once calibrated, HYDROTEL was used to generate future summer ${ }_{7 d} Q_{\min }$ for each of the 32 164 selected climate simulations, with the different equifinal sets of parameters computed during 165 the calibration process. Precipitation and minimum and maximum temperatures came from 
the climate simulations. They were computed using an average of the nearest three neighbors

167 routine to compute values for each RHHU. To further characterize the capacity of HYDROTEL to simulate flows inducing the observed ${ }_{7 d} Q_{\min }$, the latter were plotted against ${ }_{7 \mathrm{~d}} \mathrm{Q}_{\min }$ series calculated using the calibration/validation dataset as well as the equifinal sets of parameters. This allowed for the characterization of a possible bias in the modeled ${ }_{7 d} Q_{\text {min. }}$. As this paper focuses on the assessment of future ranges of ${ }_{7 d} Q_{\min }$, and not prediction of annual values, this bias was then corrected, only for the median ${ }_{7 d} Q_{\min }$ to match between modeled and observed values and not to correct the whole distribution as is done for the climate simulations with quantile-quantile mapping techniques (subsection 2.2).

\subsection{Statistical framework: alternative approach}

\section{2.4.1. Setting of the methodology}

177 This alternative approach allows for the assessment of HDIs directly from CDIs following the 178 methodology introduced in Foulon et al. (2018). It was applied to assess future summer ${ }_{7 d} Q_{\min }$ 179 at the station closest to the inlet of Château d'Eau. Observed hydrometric and climate data for 180 the period 2001-2015, which is then later referred to as the reference period, were used to 181 compute the series of observed summer ${ }_{7 d} Q_{\min }$ and CDIs. Correlations were computed 182 between the observed CDIs and ${ }_{7 d} Q_{\min }$ to capture their statistical relationship. For the future 183 period, the 32 selected climate simulations were used to compute the distributions of future 184 CDIs that were in turn used to assess the distribution of future ${ }_{7 d} Q_{\min }$ given the statistical 185 relationship derived from observed values.

186 This methodology is based on stationarity assumptions with respect to landcover, and derived 187 statistical relationships between CDIs and HDIs. The same assumption is used for the 188 conventional approach with respect to the calibration parameter values. These are discussed 189 later on in this paper. 


\subsubsection{Climate data indices}

Table 2 introduces the CDIs used in this study. They are divided into three categories with respect to the type of input data needed for their computation, that is CDIs computed from: (i) precipitation data, (ii) blended data (both precipitation and temperature), and (iii) drought indices formulas. Other CDIs could be included if other HDIs were to be studied, illustrating 195 the flexibility of the methodology. Readers are referred to Foulon et al. (2018) for more 196 details.

197 Table 2 Overview of the CDI groups used

\begin{tabular}{llll}
\hline & Precipitation data & Blended data & Drought Indices \\
\hline & & & 8. EDI (Byun and Wilhite 1999) \\
& & 3. PET & 9. EDI computed from rainfall \\
1. Cumulative rainfall & 4. Climatic demand (R-PET) & and snowmelt \\
& 5. Snowmelt & 10. EDI computed from climatic \\
& 2. Cumulative snowfall & 6. Snowmelt and rainfall & demand \\
& & 7. Snowmelt and rainfall minus & 11. EDI computed from rainfall \\
& & PET & and snowmelt minus PET \\
\hline
\end{tabular}

$R$ stands for rainfall, $P E T$ for potential evapotranspiration, $E D I$ for effective drought index.

The CDIs introduced in Table 2 were computed over one to six days, one to three weeks, one to six months, and for eight, ten and twelve months. They were then used to compute the Pearson correlations $r$ with observed $7_{\mathrm{d}} \mathrm{Q}_{\min }$ over the reference period. To further characterize the capacity of the CDIs to assess future ${ }_{7 d} Q_{\min }$ from modeled meteorological data, Pearson correlations $r$ between with the modeled CDIs and ${ }_{7 \mathrm{~d}} \mathrm{Q}_{\min }$ were computed and compared to the observed correlations through a Wilcoxon rank-sum test (Mann and Whitney 1947).

205 Once the CDI that best reproduces observed ${ }_{7 d} Q_{\min }$, in terms of explained variability, is 206 identified, a linear regression is computed in order to assess future ${ }_{7 d} \mathbf{Q}_{\min }$ from modeled 207 meteorological data. The alternative method is not intended as a replacement for the 208 conventional approach, but rather as a simpler, less technically intensive method. The 209 regression is not used to predict future ${ }_{7 d} Q_{\min }$ values, but rather assess future ranges of ${ }_{7 d} Q_{\min }$. As such, future ranges are associated with their confidence bounds computed from mean distributions and not from prediction bounds computed for the prediction of single values. 


\subsection{Evaluation of source water supply sensitivity to low flows}

1

213 Future water supply sensitivity to low flows is evaluated through the computation of a 214 pressure index. Pressure on the resource is higher when daily water abstraction is close to low 215 flows and is evaluated using the following index:

$216 \quad \mathbf{P I}_{\mathbf{1}}=\frac{\mathbf{Q}_{2-7}}{\mathrm{~A}}$ Eq 2

217 where $A$ is the summer daily mean water abstraction $\left(\mathrm{m}^{3} / \mathrm{s}\right), P I_{1}$ stands for pressure index 218 one.

219 This pressure index is used by the Quebec Government to assess whether water can be 220 abstracted from a specific source and used as well by Bérubé (2007); Nantel (2006) to 221 evaluate historical pressure on surface water resources across Québec.

222 To avoid adding another source of uncertainty to the modeling chain used in this paper, 223 probability distributions were not used to fit the series of ${ }_{7 d} Q_{\min }$. Instead, $\mathrm{Q}_{2-7}$ was obtained for 224 the periods 2016-2045 (referred to as horizon 2030) and 2046-2075 (horizon 2060) from the 225 flows empirical cumulative frequencies computed from the probability function introduced by 226 Cunnane (1978):

$\mathbf{P}=(\boldsymbol{r}-\mathbf{0 . 4}) /(\boldsymbol{N}+\mathbf{0 . 4})$

228 where $r$ and $N$ stand for the rank and the number of observations, respectively. 


\section{Results}

\subsection{Hydrological modeling and behavioral models}

This subsection ascertains the capacity of HYDROTEL to assess future summer $7 \mathrm{~d} \mathbf{Q}_{\min }$. Presentation of climate data characteristics is beyond the scope of this paper; they can be found in Online Resource 1.

\subsubsection{Parameter equifinality}

Following the automatic calibration and parameter sets generation methodology introduced in subsection 2.3.2, estimates of the pseudolikelihood function for each subwatershed were established $-0.800,0.850,0.746$ and 0.785 for Des Hurons, Nelson, Jaune, and St. Charles, respectively. 16 optimization trials lead to the identification of behavioral solutions. This number was deemed sufficient on account of: (i) the range covered by the 16 behavioral sets of parameters introduced in Online Resources 2 and (ii) the ensuing calibration/validation results (Table 3).

\section{3.1.2. Calibration and validation results}

Model performances for calibration and validation periods are given in Table 3. For each river 245 segment, according to the hydrologic model performance rating of Moriasi et al. (2007), all 246 results, but for the validation of Jaune River, provided a "very good fit" $(\mathrm{OF}>0.75)$. Nash-log247 7-day values belong to ranges narrower than 0.03 and 0.04 for calibration and validation, 248 respectively. Performances exhibited a maximum difference of $3 \%$ between calibration and 249 validation. Moreover, the validation performances sometimes increased in comparison with 250 calibration values; Des Hurons validation performances were even a median $2 \%$ better than 251 those of the calibration period (negative median performance loss in Table 3). These results 252 vouch for the quality of the identified behavioral solutions as highlighted in Beven (2006). 
Table 3 Median model performances [ $\min -\max ]$ for the calibration and validation periods

\begin{tabular}{cccccc}
\hline River segment & $\begin{array}{c}\text { Calibration } \\
\text { period }\end{array}$ & Nash-log-7-day & $\begin{array}{c}\text { Validation } \\
\text { period }\end{array}$ & Nash-log-7-day & $\begin{array}{c}\text { Performance } \\
\text { loss (median) }\end{array}$ \\
\hline Des Hurons & $2012-2016$ & $0.810[0.801-0.825]$ & $2007-2011$ & $0.826[0.804-0.832]$ & $-2 \%$ \\
Jaune & $1990-1994$ & $0.750[0.747-0.752]$ & $1985-1989$ & $0.735[0.722-0.749]$ & $2 \%$ \\
Nelson & $2012-2016$ & $0.855[0.851-0.858]$ & $2007-2011$ & $0.830[0.813-0.840]$ & $3 \%$ \\
\hline St. Charles & $2012-2016$ & $0.790[0.786-0.796]$ & $2007-2011$ & $0.764[0.743-0.783]$ & $3 \%$ \\
& & & $2002-2006$ & $0.787[0.781-0.795]$ & $1 \%$ \\
\hline
\end{tabular}

\section{3.1.3. Duplication of the observed HDIs}

256 The capacity of HYDROTEL to correctly reproduce low flows for the St. Charles gauging 257 station (Fig. 1) was assessed. Fig. 2 introduces boxplots computed using the 16 different 258 behavioral models. It shows that the distributions of modeled ${ }_{7 d} Q_{\min }$ over 2002-2016 259 (calibration and validation periods) represent fairly well the observed values. Indeed, out of 260 the 15 years, the modeled distribution covered the observed values (taking into account their 261 inherent error due to the standard deviation of the average flows on 7 days) for 12 years out of 26215 ; that is $80 \%$ of the observed values. In details, modeled ${ }_{7 d} Q_{\min }$ for years 2007 and 2008 263 overpassed observed values with a median ratio of 0.8 and 0.35 , respectively. For the year 2642009 , modeled ${ }_{7 d} Q_{\min }$ were smaller than observed values with a median ratio of 0.7 . It is also 265 interesting to note that interannual tendencies (whether the observed values increase from one 266 year to the next) are mostly replicated. Indeed, apart from the transition from 2006 to 2007, 2672009 to 2010 and 2013-2014, interannual evolutions of observed values were reproduced by 268 the computed distributions. Last, the positive bias $(23 \%)$ exhibited by the modeled 269 distributions over the observed values were corrected as defined in subsection 2.3.3 
$270 \quad$ Fig. 2 Boxplot of the HDIs computed using 16 sets of parameter values for the St. Charles River watershed during the
271
calibration/validation period. Blue dots stand for the HDI computed from observed data while triangles represent the

\section{from observed and modeled meteorological data, respectively}

Table 4 Pearson correlations $r$ and median Pearson correlations between observed summer ${ }_{7 d} Q_{\min }$ and CDIs computed

\begin{tabular}{llcc}
\hline $\begin{array}{c}\text { Input Variable } \\
\text { Category }\end{array}$ & \multicolumn{1}{c}{ CDI } & $\begin{array}{c}\text { Reference: } \\
\mathbf{2 0 0 1 - 2 0 1 5}\end{array}$ & $\begin{array}{c}\text { Modeled: } \\
\mathbf{2 0 0 1 - 2 0 1 5}\end{array}$ \\
\hline \multirow{2}{*}{$\begin{array}{l}\text { Precipitation data } \\
\text { 1. Cumulative rainfall 8 months }\end{array}$} & 0.62 & 0.66 \\
& 2. Cumulative rainfall 10 months & 0.61 & 0.62 \\
\hline \multirow{2}{*}{ Blended data } & 4. R-PET 2 months & 0.82 & 0.87 \\
& 5. R-PET 3 months & 0.75 & 0.81 \\
\hline \multirow{2}{*}{ Drought Indices } & 6. EDI from climatic demand 8 months & 0.68 & 0.71 \\
& 7. EDI from climatic demand 10 months & 0.70 & 0.71 \\
\hline
\end{tabular}

The Wilcoxon rank-sum test failed to provide evidence (at the 5\% significance level) that median modeled and observed correlations were different

Given the results introduced in Table 4, the CDI R-PET over 2 months was used to compute a linear regression with the observed ${ }_{7 d} Q_{\text {min. }}$ Fig. 3 shows that all observed ${ }_{7 d} Q_{\text {min }}$ were reproduced by the linear regression, but for two values that correspond to years 2007 and 2009, as for the duplication of the observed HDI within the conventional approach. It is noteworthy the regression was carried out under the constraint of being positive to comply with the physical reality of non-negative flows. 
Fig. 3 Linear regression between the observed ${ }_{7 d} Q_{\min }$ and the cumulative R-PET over 2 months. Triangles represent the error associated with observed values. Confidence bounds are presentes at $95 \%$

\subsection{Conventional and alternative approaches}

This subsection now focuses on the evolutions between the reference period and future horizons before evaluating the sensitivity of the surface water supply to low flows in terms of $\mathrm{Q}_{2-7}, \mathrm{Q}_{10-7}$ and derived pressure indices.

\subsubsection{Low flow evolutions from reference to future horizons 2030 and 2060}

Fig. 4 shows that modeled $7 \mathrm{~d} \mathrm{Q}_{\min }$, for both approaches, were not statistically different $(\mathrm{p}<0.05$ for Wilcoxon tests) from observed values nor from one another for RCP-4.5 and RCP-8.5, which is not surprising given that ${ }_{7 d} \mathrm{Q}_{\min }$ issued from the conventional approach were bias corrected for each climate simulation as introduced in subsection 2.3.3. Both the conventional and alternative approaches assess a significant decrease in median ${ }_{7 d} Q_{\min }$ from the reference period to the future horizons 2030 and $2060\left(\mathrm{p}<3.10^{-4}\right)$. Although there was a significant difference $(\mathrm{p}<0.03)$ between the modeled medians of each approach for both RCPs and both future horizons, these differences are relatively small (the maximum difference was 0.18 between approaches in 2016-2045 for RCP-4.5) compared to the whole boxplot range or even to the interquartile range that arose from interannual variability. Last, with the exception of the conventional approach in 2016-2045, the two approaches computed significant differences $\left(\mathrm{p}<2.10^{-3}\right)$ between similar horizons for RCP-4.5 and RCP-8.5. Fig. 4 Boxplots of the ${ }_{7 d} Q_{\min }$ computed for the reference period (2001-2015), and two future periods (2016-2045 and
2046-2075) from observed flow data (pink), the conventional approach (black), and the alternative approach (cyan) for RCP-4.5 and RCP-8.5

Interannual variabilities are depicted by boxplot ranges. Despite being able to reproduce the median obtained from the conventional approach, the alternative approach did not replicate well this interannual variability. This can be seen as the inherent limit to the use of a regression model that is, by definition, computed to best reproduce the mean relationship 317 between variables. 


\subsubsection{Equifinality and confidence intervals}

Fig. 5 introduces the future $7 \mathrm{~d} \mathrm{Q}_{\min }$ medians assessed using the conventional and alternative approaches for RCP-4.5 and RCP-8.5. Magenta, black and cyan shaded areas were computed to cover the observational uncertainty, equifinality, and confidence intervals of the regression coefficients, respectively. Observational uncertainty was comparable to that of the regression while uncertainty arising from equifinality was much smaller for all the study period and both RCPs. As was the case for the previous subsection, evolutions of the ${ }_{7 d} Q_{\min }$ under RCP-4.5 and RCP-8.5 were similar for both approaches. Indeed, the evolution trajectory and bounds predicted by the conventional approach were almost entirely included within the bounds of the alternative approach (except in 2016-2045 for RCP-4.5). Last, both trajectories, even that computed from extreme lines for the alternative approach, indicate a significant decrease in five-year ${ }_{7 \mathrm{~d}} \mathrm{Q}_{\min }$ medians ( $\mathrm{p}<0.01$ for Mann-Kendall tests).

Fig. 5 Median future $7 \mathrm{~d} \mathrm{Q}_{\min }$ assessed using the conventional (black) and alternative (cyan) approaches for RCP-4.5 and RCP-8.5

332 3.3.3. Sensitivity to low flows of the surface water supply

333 This subsection provides a framework to summarize the results for both approaches in terms

334 of the future sensitivity to low flows of the surface water supply of Château d'Eau. ${ }_{7 d} Q_{\min }$ 335 series were transformed into hydrological data indices associated with a return period (Table $3365)$ 
Table 5 Median pressure index under current climate conditions (Reference period - 2001-2015) and change (\%) under future climate conditions (horizons 2030 and 2060)

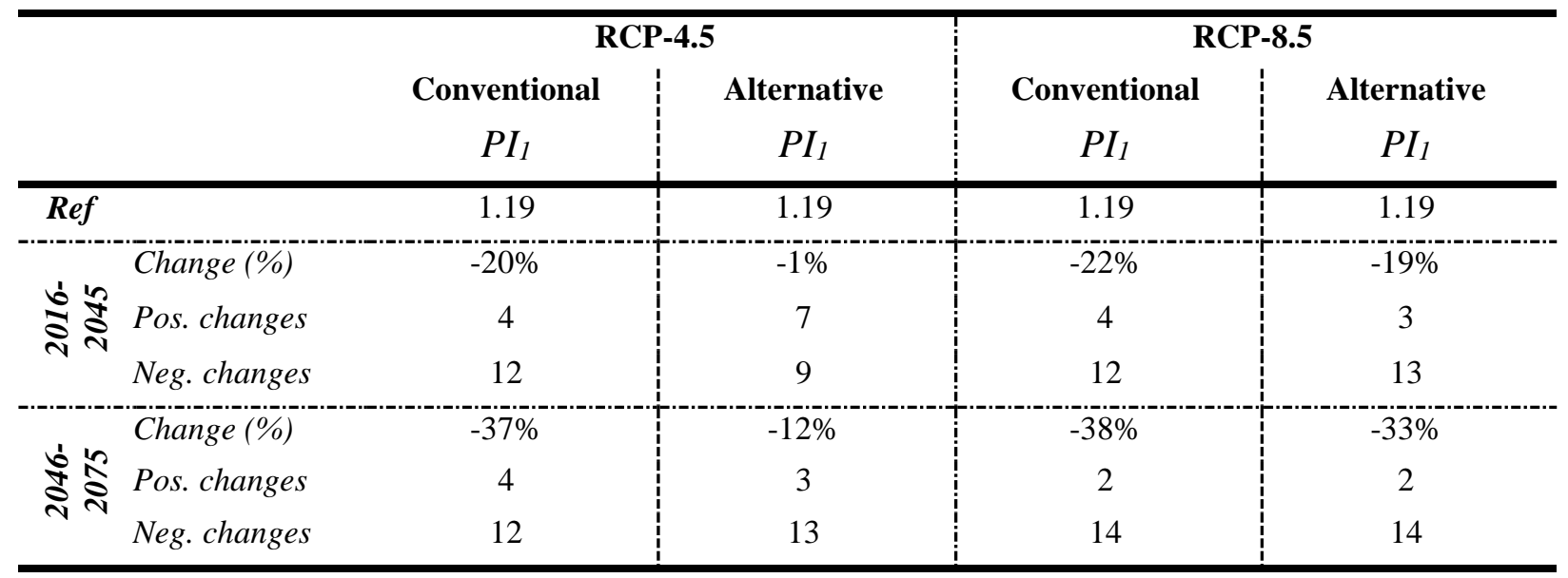

340 Conventional as well as alternative approaches predict decreasing $P I_{l}$ for both RCPs and future horizons. This result emerged from Fig. 4 and is quantified in Table 5. With respect to 342 the reference period, $P I_{1}$ decreased, for RCP-4.5, medians of $20 \%$ (horizon 2030) and $37 \%$ 343 (horizon 2060), and medians of $1 \%$ (horizon 2030) and 12\% (horizon 2060) for the conventional and alternative approaches, respectively. Similarly, $P I_{l}$ decreased, for RCP-8.5, 345 medians of $22 \%$ and $38 \%$, and medians of $19 \%$ and $33 \%$ for the conventional and alternative 346 approaches, respectively. Differences in these assessed changes are quite high for RCP-4.5 347 especially. But mean changes (computed from the individual $P I_{1}$ assessed for each climate model) were closer with mean decreases of 9 and $23 \%$, and 0 and $16 \%$ for the conventional and alternative approaches, respectively.

350 To avoid masking differences between models by aggregating results into a median change, 351 the number of models conveying positive or negative changes was also provided. It shows 352 that overall the two approaches are consistent in terms of relative agreement with respect to 353 the direction of change. But, for RCP-4.5, for the horizon 2030, four (4) models assessed a 354 positive change, 12 a negative change, against seven (7) for a positive change, nine (9) for a 355 negative change, for the conventional and alternative approaches, respectively. 


\section{Discussion}

The following sections deal with: (i) the main assumptions made throughout the paper, (ii) the relevance of the alternative methodology in comparison with the conventional approach, and (iii) the inherent limit associated with a regression model.

\subsection{The issue of non-stationarity}

Non-stationarity is an inherent issue of the conventional approach with respect to climate and landcover evolutions; while stationarity is an inherent issue of the alternative approach in terms of the captured statistical relationships. In this paper, meteorological data were the only varying characteristic of the modeling set up. We assumed that non-stationarity with respect to climate should not impact model parameters considering that: (i) only one calibrated parameter - that related to evapotranspiration - was linked to variation in meteorological data and (ii) relatively similar ranges of mean annual/seasonal temperature and precipitation were found for both the calibration/validation period and the future period. Also, the consideration of equifinality showed that similar performances could be achieved (interval width lower than 0.03 , even in validation) with very different sets of parameter values (Online Resource 2) 371 despite the careful consideration given to the number of calibration parameters. With respect 372 to landcover, defining future scenarios that would allow accounting for changes through time 373 was beyond the scope of this paper. Nonetheless, as showed by Blanchette et al. (2018), over 374 reference period was limited to 2001-2015 during which the distribution of landcover did not change much (Blanchette et al. 2018). 


\subsection{Conventional and alternative approaches}

Median results of the conventional and alternative approaches are similar (section 3.3.1).

What is also apparent is the relative inability of the alternative approach to capture interannual variabilities. That being said, for both RCPs, the conventional and alternative approaches modeled an increase in interannual variabilities from the reference period to the horizon 2030 and a decrease from the latter horizon to horizon 2060. These changes in interannual variabilities are much higher than median changes and are valuable to water managers: at this temporal scale (30-year horizons), interannual variations, pertaining to the chaotic nature of climate, are overriding the CC (climate change) signal.

Results obtained for 5-year periods demonstrate other similarities between the two approaches (section 3.3.2). Indeed median trajectories assessed using both methods indicate a significant linear decrease in ${ }_{7 d} Q_{\min }$ medians, showing that overall the $\mathrm{CC}$ signal is still apparent and that water managers should plan for this decrease accordingly. For both approaches, this is even more apparent for RCP-8.5, because RCP-4.5 exhibits two rather important hiccups. We remind the readers that RCP-4.5 and -8.5 are the "optimistic" and "business as usual" scenarios associated with concentration pathways twice and four times their current levels for the 2100 horizon (IPCC 2014), respectively. Expected impacts in terms of ${ }_{7 d} Q_{\min }$ seem rather ineluctable for horizon 2030 given the small differences between RCPs. Differences become more significant further into the future. Nonetheless, Fig. 5 also depicts a major divergence with respect to confidence bounds associated with both methods. Indeed, the conventional approach confidence bounds are smaller than those of the alternative approach. Including hypothetical measurement errors within the former (as the standard deviation of the averaged 402 flows on 7 days) would render the confidence bounds comparable as demonstrated in Online 403 Resources 3. Moreover, uncertainty related to the structure of hydrological models would 404 probably expand the bounds of the conventional approach. Yet, as the objective of this paper 
and of the methodology introduced by Foulon et al. (2018) was to bypass the hydrological modeling, it was deemed inappropriate to use a second hydrological model.

Finally, for all future horizons, whether we consider the alternative approach or the conventional approach (Table 5), results obtained for RCP-8.5 are rather worrying. Indeed, they indicate a decrease of around 20\% (2016-2045) and 35\% (2046-2075) with a fairly high confidence (around $90 \%$ of models agreeing on the direction of change) for $P I_{1}$. This would lead in both cases to $P I_{I}$ being less than 1, indicating an insufficient water supply with respect to available water during 2-year low flows. This result, not taking into account the possible increase in future water demand, should mandate the planning of alternative water supply solutions to relieve this anticipated stress on future water supply from Château d'Eau.

\section{4.3. Linear regression, how to assess extreme quantiles evolution?}

416 In addition to the $\mathrm{Q}_{2-7}$, the MDDELCC uses the $\mathrm{Q}_{10-7}$, to evaluate the exceedance of water 417 quality criteria in case of pollutant discharges (MDDEP 2007). From this HDI, a second 418 pressure index $\left(P I_{2}\right)$ could be computed, replacing $\mathrm{Q}_{2,7}$ by $\mathrm{Q}_{10,7}$ in Equation (2) (section 2.5). 419 But, as the $\mathrm{Q}_{10,7}$ is associated with a non-exceedance probability of 0.1 , this would mean 420 assessing future $P I_{2}$ from the highest $10 \%$ values of the linear regression; that is 1 or two data 421 points. On top of that, by definition, a regression model is meant to reproduce the mean 422 relationship between variables. That is why $P I_{2}$, for this case study, was not computed for the 423 alternative approach, but only for the conventional approach. $P I_{2}$ was 1.05 for the reference 424 period. For RCP-4.5, with respect to the reference period, $P I_{2}$ decreases with a median of $10 \%$ 425 (seven (7) models assessing a positive change against nine (9) for a negative change), and negative assessments). 
430 This type of results could be obtained using linear regression if more data were available

during the reference period. Besides, quantile regression (QR,(Koenker 2005)) would be an interesting method to test in the context of providing alternative approaches to the hydroclimatological methodology. The difference between QR and regression is that QR can estimate different regression lines with respect to the different quantiles. This allows capturing the complexity of statistical relationships between two variables beyond the mean. It would allow, for basins from the Reference Hydrometric Basin Network (RHBN, (Environnement Canada 2012)) for example, assessing separately the effects of CDIs on ${ }_{7 \mathrm{~d}} \mathrm{Q}_{\min }$ with different return periods.

\section{Conclusion}

In this paper, two approaches were applied to the case study of the Château d'Eau surface water supply of Québec City during summer low flows (June to November). The conventional approach is the quasi standard methodology used since publication of the IPCC AR4 report. The alternative approach does not require hydrological modeling and can thus be applied by any water organization because of the limited required expertise. Future climate was built for two emission scenarios RCP-4.5 and -8.5, and uncertainty of the climate change (CC) signal was addressed through the use of 16 climate models.

Overall, the low flow evolutions assessed from reference to future horizons (2016-2045 and 2046-2075) were very similar for both methods. 7d $Q_{\min }$ medians decreased from one horizon to the other, but interannual variabilities were much larger than the median decrease, indicating that, at this this temporal scale (30-year horizons), the chaotic nature of climate is overriding the $\mathrm{CC}$ signal. Given the nature of the alternative method, computed to reproduce 452 the mean relationship between variables, interannual variabilities were less well represented. 453 For 5-year periods, both methods assessed a significant decrease in five-year $7 \mathrm{~d} \mathrm{Q}_{\min }$ medians 
showing that overall the CC signal was still apparent within results, especially for RCP-8.5 which is the "pessimistic scenario". As for the confidence bounds associated with each approach, they reflected the impact of equifinality and of the confidence interval for the regression coefficients for the conventional and alternative methods, respectively. The confidence bounds of the conventional approach were smaller than those of the alternative approach, but could expand if the uncertainties associated with measurement errors and hydrological model structure were taken into account. Despite this difference, both methods agreed: the future pressure on the surface water supply of Québec City from Château d'Eau is worth worrying. Indeed, for RCP-8.5, they indicated a decrease of around 20\% (2016-2045) and $35 \%$ (2046-2075) with a fairly high confidence (around 90\% of models agreeing on the direction of change) for $P I_{l}$; indicating, even for the near future, an insufficient water supply with respect to available water during 2-year low flows.

The alternative approach assessed very similar results to that of the conventional approach. It can easily be applied to any hydrometric station with sufficient data. This reinforces the assessment made in Foulon et al. (2018) pertaining to the capacity of the method to provide a screening assessment of future drought-prone-watersheds; that is those that could benefit from an in-depth hydroclimatic modeling study. Furthermore, the application of the alternative approach would help spread good management practices even for small municipalities that do 472 not have the capacities to conduct the more formal conventional approach. This paper 473 contributes to the advancement of climate change adaptation, providing an alternative 474 approach that could help prevent last minute emergency actions, by providing a framework to 475 plan for future surface water supply sensitivities to low flows given climate simulations. 
1

2

3477 Conflict of Interest - None

5

6
7 48

8

9

10

11

12

13

14

15

16

17

18

19

20

21

22

23

24

25

26

27

28

29

30

31

32

33

34

35

36

37

38

39

40

41

42

43

44

45

46

47

48

49

50

51

52

53

54

55

56

57

58

59

60

61

62

63

64

65

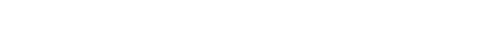

\section{Conflict of Interest Statement}




\section{References}

Bérubé J (2007), Evaluation d'un indice de pression sur les approvisionnements municipaux en eau potable au Québec à l'aide d'une méthode de régionalisation des débits d'étiage, Maîtrise, 101 pp, INRS, Québec.

Beven K (2006) A manifesto for the equifinality thesis Journal of Hydrology 320:18-36 doi:10.1016/j.jhydrol.2005.07.007

Beven K, Freer J (2001) Equifinality, data assimilation, and uncertainty estimation in mechanistic modelling of complex environmental systems using the GLUE methodology Journal of Hydrology 249:11-29

Blanchette M, Rousseau A, Foulon E, Savary S, Poulin M (2018) Long-term assessment of the impact of land cover change on the hydrological services provided by wetlands Environmental Management Under Review

Blöschl G, Montanari A (2010) Climate change impacts - throwing the dice? Hydrological Processes 24:374-381 doi:10.1002/hyp.7574

Brodeur C, Brassard D, Dionne N, Laberge V, Labrecque R, Trépanier J, Turmel P (2012), Portrait des bassins versants de la Capitale, Organisme des bassins versants de la Capitale.

Byun HR, Wilhite DA (1999) Objective quantification of drought severity and duration Journal of Climate 12:2747-2756

CEHQ (2015), Hydroclimatic Atlas of Southern Québec. The Impact of Climate Change on High, Low and Mean Flow Regimes for the 2050 horizon, 81 pp, Québec.

COBAMIL (2014), Problèmes prioritaires, orientations et objectifs du PDE de la zone de gestion intégrée de l'eau par bassins versants du COBAMIL, $18 \mathrm{pp}$, Conseil des bassins versants des Mille-Îles, Sainte-Thérèse, Québec.

Côté B, Leconte R, Trudel M (2013), Développement d'un prototype de système d'alerte aux faibles débits et aux prélèvements excessifs dans le bassin versant pilote de la rivière Yamaska, 111 pp, Université de Sherbrooke.

Cunnane C (1978) Unbiased plotting positions - A review Journal of Hydrology 37:205-222 doi:https://doi.org/10.1016/0022-1694(78)90017-3

Dobler C, Hagemann S, Wilby RL, Stötter J (2012) Quantifying different sources of uncertainty in hydrological projections in an Alpine watershed Hydrol Earth Syst Sci 16:4343-4360 doi:10.5194/hess-16-4343-2012

Ehret U, Zehe E, Wulfmeyer V, Warrach-Sagi K, Liebert J (2012) HESS Opinions "should we apply bias correction to global and regional climate model data?" Hydrology and Earth System Sciences 16:3391-3404 doi:10.5194/hess-16-3391-2012

Environnement Canada (2012) The hydrometric network. https://www.canada.ca/en/environment-climate-change/services/water- 
overview/quantity/monitoring/survey/hydrometric-program-nationalpartnership/network.html. Accessed December, 122017

Fortin J-P, Turcotte R, Massicotte S, Moussa R, Fitzback J, Villeneuve J-P (2001) A distributed watershed model compatible with remote sensing and GIS data. Part I: Description of the model Journal of Hydrologic Engineering 6:91-99

Foulon E, Rousseau AN (2018) Equifinality and automatic calibration: What is the impact of hypothesizing an optimal parameter set on modelled hydrological processes? Canadian Water Resources Journal 43:47-67 doi:10.1080/07011784.2018.1430620

Foulon E, Rousseau AN, Gagnon P (2018) Development of a methodology to assess future trends in low flows at the watershed scale using solely climate data Journal of Hydrology 557:774-790 doi:http://dx.doi.org/10.1016/j.jhydrol.2017.12.064

Huard D (2010), Tributaires du St-Laurent - Documentation Release 0.2, 17 pp, Ouranos.

Hutchinson MF, McKenney DW, Lawrence K, Pedlar JH, Hopkinson RF, Milewska E, Papadopol P (2009) Development and testing of Canada-wide interpolated spatial models of daily minimum-maximum temperature and precipitation for 1961-2003 Journal of Applied Meteorology and Climatology 48:725-741

Institut de la statistique du Québec (2015) Profils statistiques par région et MRC géographiques.

http://www.stat.gouv.qc.ca/statistiques/profils/region_00/region_00.htm. Accessed October 2017

IPCC (2007), Climate Change 2007: Synthesis Report. Contribution of Working Groups I, II and III to the Fourth Assessment Report of the intergovernmental Panel on Climate Change, 104 pp, IPCC, Geneva, Switzerland.

IPCC (2014), Climate Change 2014: Impacts, Adaptation and Vulnerability. Part A: Global and Sectoral Aspects. Contribution of Working Group II to the Fifth Assessment Report of the Intergovernmental Panel on Climate Change, $1132 \mathrm{pp}$, Cambridge, United Kingdom and New York, NY, USA.

Koenker R (2005), Quantile regression, 1-368 pp., Cambridge University Press.

Kundzewicz ZW et al. (2007) Freshwater resources and their management. In: Parry ML, Canziani OF, Palutikof JP, van der Linden PJ, Hanson CE (eds) Climate Change 2007: Impacts, Adaptation and Vulnerability. Contribution of Working Group II to the Fourth Assessment Report of the Intergovernmental Panel on Climate Change. Cambridge University Press, Cambridge, UK, pp 173-210

Mann HB, Whitney DR (1947) On a Test of Whether one of Two Random Variables is Stochastically Larger than the Other Ann Math Statist 18:50-60 doi:10.1214/aoms/1177730491

MDDELCC (2016) Bilan de la qualité de l'eau potable au Québec 2010-2014. http://www.mddelcc.gouv.qc.ca/eau/potable/bilans/bilan-qualite2010-2014.pdf. Accessed October 2017 
MDDEP (2007) Calcul et interprétation des objectifs environnementaux de rejet pour les contaminants en milieu aquatique. Québec, ministère du Développement durable, de l'Environnement et des Parcs, Direction du suivi de l'état de l'environnement,. http://www.mddelcc.gouv.qc.ca/eau/oer/Calcul_interpretation_OER.pdf. Accessed Octobre 2017

Moriasi DN, Arnold JG, VanLiew MW, Bingner RL, Harmel RD, Veith TL (2007) Model evaluation guidelines for systematic quantification of accuracy in watershed simulations Transactions of the ASABE 50:885-900

Mpelasoka FS, Chiew FHS (2009) Influence of rainfall scenario construction methods on runoff projections Journal of Hydrometeorology 10:1168-1183 doi:10.1175/2009JHM1045.1

Nantel E (2006) Elaboration d'une méthode d'estimation des vulnérabilités historiques des approvisionnements en eau potable au Québec. Maîtrise, INRS

Ouranos (2016), Bilan hydrologique des rivières Saint-Charles et Montmorency dans un contexte de changements climatiques, Rapport présenté à la Communauté métropolitaine de Québec, $44+$ annexes pp.

Riahi K et al. (2011) RCP 8.5-A scenario of comparatively high greenhouse gas emissions Climatic Change 109:33 doi:10.1007/s10584-011-0149-y

Ricard S, Bourdillon R, Roussel D, Turcotte R (2013) Global calibration of distributed hydrological models for large-scale applications Journal of Hydrologic Engineering 18:719-721

Salou BIG (2009) Estimation des apport au lac Saint-Charles à l'aide du modèle hydrologique SWAT. Université Laval

Smakhtin VU (2001) Low flow hydrology: a review Journal of Hydrology 240:147-186 doi:https://doi.org/10.1016/S0022-1694(00)00340-1

Staudinger M, Stahl K, Seibert J, Clark MP, Tallaksen LM (2011) Comparison of hydrological model structures based on recession and low flow simulations Hydrol Earth Syst Sci 15:3447-3459 doi:10.5194/hess-15-3447-2011

Teng J, Vaze J, Chiew FHS, Wang B, Perraud J-M (2012) Estimating the Relative Uncertainties Sourced from GCMs and Hydrological Models in Modeling Climate Change Impact on Runoff Journal of Hydrometeorology 13:122-139 doi:10.1175/jhmd-11-058.1

Thomson AM et al. (2011) RCP4.5: a pathway for stabilization of radiative forcing by 2100 Climatic Change 109:77 doi:10.1007/s10584-011-0151-4

Todd MC, Taylor RG, Osborn TJ, Kingston DG, Arnell NW, Gosling SN (2011) Uncertainty in climate change impacts on basin-scale freshwater resources - preface to the special issue: the QUEST-GSI methodology and synthesis of results Hydrol Earth Syst Sci 15:1035-1046 doi:10.5194/hess-15-1035-2011 
Tolson BA, Shoemaker CA (2007) Dynamically dimensioned search algorithm for computationally efficient watershed model calibration Water Resources Research 43 doi:10.1029/2005WR004723

Tolson BA, Shoemaker CA (2008) Efficient prediction uncertainty approximation in the calibration of environmental simulation models Water Resources Research 44 doi:10.1029/2007WR005869

Turcotte R, Fortin LG, Fortin V, Fortin JP, Villeneuve JP (2007) Operational analysis of the spatial distribution and the temporal evolution of the snowpack water equivalent in southern Québec, Canada Nordic Hydrology 38:211-234 doi:10.2166/nh.2007.009

Turcotte R, Rousseau AN, Fortin J-P, Villeneuve J-P (2003) Development of a processoriented, multiple-objective, hydrological calibration strategy accounting for model structure. In: Duan Q, Sorooshian S, Gupta H, Rousseau AN, Turcotte R (eds) Advances in Calibration of Watershed Models. Water Science \& Application, vol no. 6. American Geophysical Union (AGU), Washinghton, USA, pp 153-163 


\title{
SURFACE WATER QUANTITY FOR DRINKING WATER DURING LOW FLOWS - SENSITIVITY ASSESSMENT SOLELY FROM CLIMATE DATA
}

\author{
Water Resources Management
}

Étienne Foulon ${ }^{{ }^{*}}(0000-0003-2509-6101)$, Alain N. Rousseau ${ }^{1}$ (0000-0002-3439-2124)

1 INRS-ETE/Institut National de la Recherche Scientifique-Eau Terre Environnement, 490 rue de la Couronne, Québec City, G1K 9A9, Québec, Canada

*Corresponding author: etiennefoulon59@gmail.com, 418-271-2687 
DDS was executed following the guidelines and implementation steps provided in Tolson and Shoemaker (2008) to quantify prediction uncertainty resulting from the acceptance of the equifinality concept. Prior to implementing these steps, an estimate of the maximum of the pseudolikelihood function was established using $1 \%$ of the model evaluation budget, i.e. a 100-repetion-trial.

- Step 1: Because of the computational time associated with HYDROTEL, the total number of model evaluations for analysis was fixed to 10,000 and the maximum required number of behavioral samples to identify was set to 100 . Thus, the number of model evaluations per DDS optimization trial was $100(10,000 / 100)-$ when guidelines suggested using from $3 D$ to $7 D$, where $D$ is the number of uncertain parameters (12 in this paper).

- Step 2: DDS was executed for 100 optimization trials (each trial was initiated from a different random set of parameter values) when 100 to 200 was suggested in the guidelines.

- Step 3: A set of parameter is deemed behavioral if the pseudolikelihood value identified in one 100-repetion-trial is higher than the estimated maximum pseudolikelihood.

- Step 4: This leads to the last subjective decision to be made: is the number of behavioral parameter sets identified acceptable? If not, the threshold of the estimated maximum pseudolikelihood can be lowered or nonbehavioral DDS solutions can be refined. 


\section{References}

Tolson BA, Shoemaker CA (2008) Efficient prediction uncertainty approximation in the calibration of environmental simulation models Water Resources Research 44 doi:10.1029/2007WR005869 


\title{
SURFACE WATER QUANTITY FOR DRINKING WATER DURING LOW FLOWS - SENSITIVITY ASSESSMENT SOLELY FROM CLIMATE DATA
}

\author{
Water Resources Management
}

Étienne Foulon ${ }^{{ }^{*}}(0000-0003-2509-6101)$, Alain N. Rousseau ${ }^{1}$ (0000-0002-3439-2124)

1 INRS-ETE/Institut National de la Recherche Scientifique-Eau Terre Environnement, 490 rue de la Couronne, Québec City, G1K 9A9, Québec, Canada

*Corresponding author: etiennefoulon59@gmail.com, 418-271-2687 
(a) RCP-4.5, 2016-2045

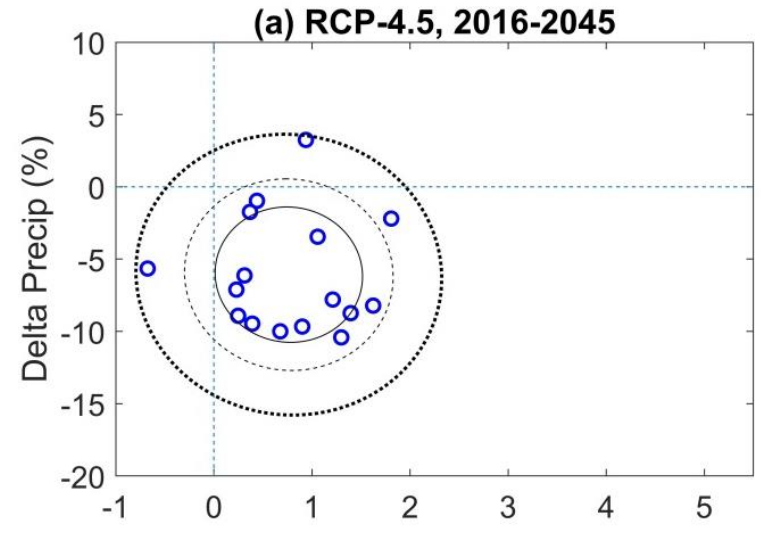

(c) RCP-8.5, 2016-2045

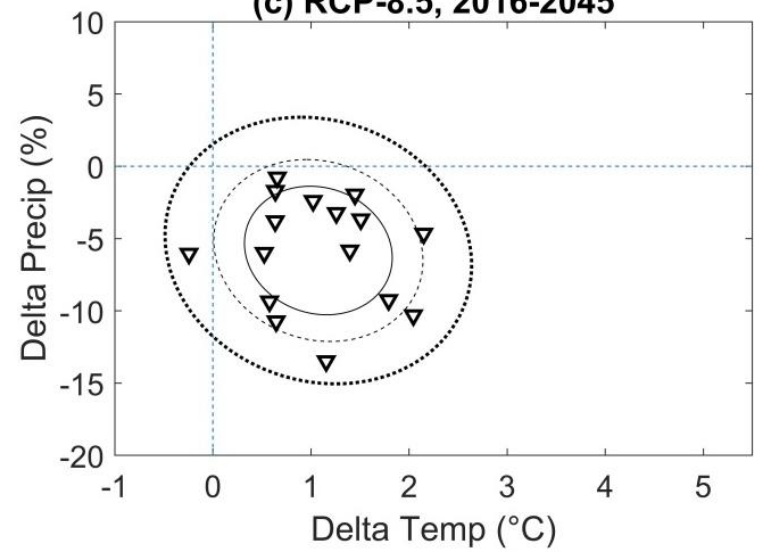

(b) 2046-2075

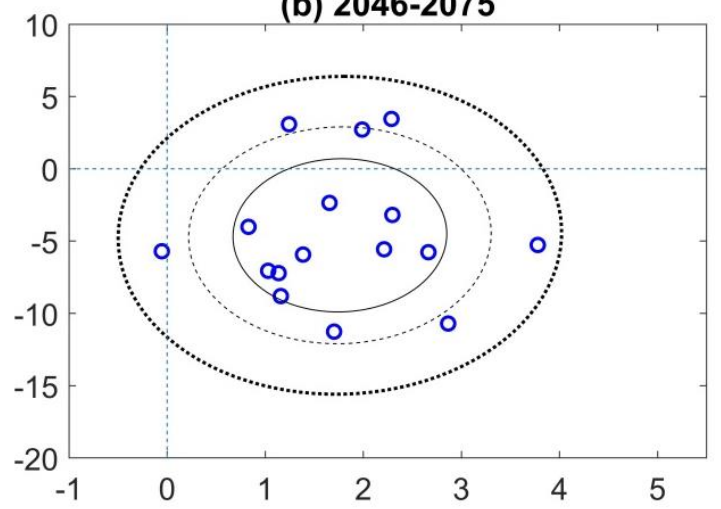

(d) 2046-2075

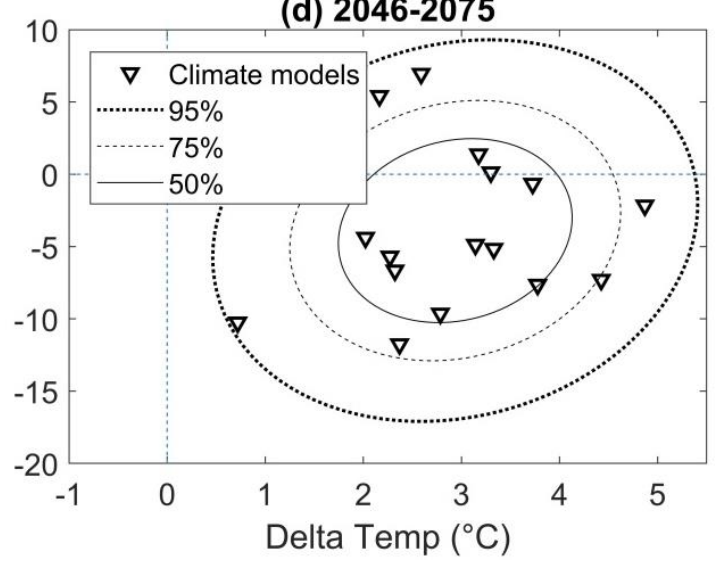

Fig. 1 Dispersion of climate models between reference (1986-2015) and future horizons (2016-2045 and 20462075) for the Saint-Charles watershed for the summer hydrological season for two RCPs. Circles stand for RCP-4.5 (a and b); triangles stand for RCP-8.5 (c and d) 


\title{
SURFACE WATER QUANTITY FOR DRINKING WATER DURING LOW FLOWS - SENSITIVITY ASSESSMENT SOLELY FROM CLIMATE DATA
}

\author{
Water Resources Management
}

Étienne Foulon ${ }^{1 *}(0000-0003-2509-6101)$, Alain N. Rousseau ${ }^{1}$ (0000-0002-3439-2124)

1 INRS-ETE/Institut National de la Recherche Scientifique-Eau Terre Environnement, 490 rue de la Couronne, Québec City, G1K 9A9, Québec, Canada

*Corresponding author: etiennefoulon59@gmail.com, 418-271-2687 
Fig. 1 shows the range covered by the identified 16 behavioral sets of parameters used in modeling the Saint-Charles River watershed. The figure was computed by putting together a radar plot of the calibration parameter values. For every set of parameters, a line was drawn to link every individual parameter value. The computation of the 16 lines made it possible to picture the range covered by the selected sets of parameters within a predefined physical interval that limited the automatic calibration algorithm. These limits were based on the information provided by past sensitivity analyses, operational experience, and calibration exercises.
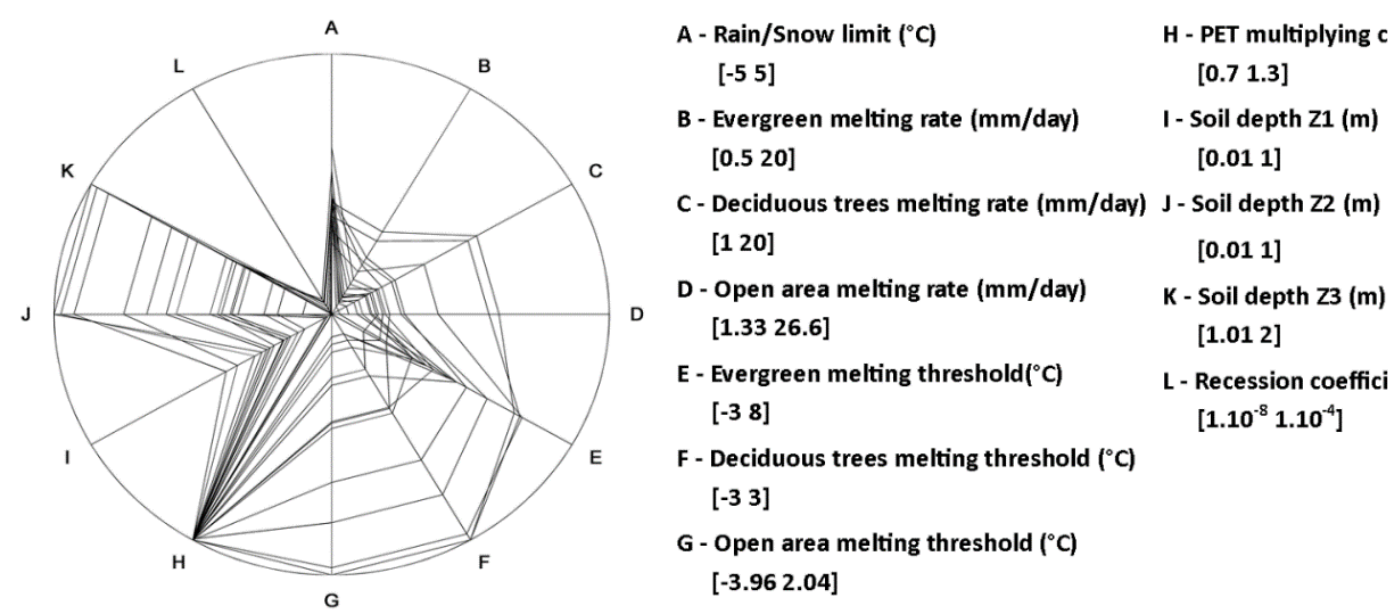

Fig. 1 Radar plot of the twelve parameters used in the automatic calibration of HYDROTEL for the SaintCharles River watershed. Parameter A is part of the interpolation coefficients, parameters $B$ through $G$ relate to the snow model, and parameters $\mathrm{H}$ through $\mathrm{L}$ relate to the soil parameters

Except for the PET multiplying coefficient and the recession coefficient $(H$ and $L$ in Fig. 1), which range covered less than $5 \%$ of the physical range, all parameters covered at least $25 \%$ of it. Parameters related to deciduous trees and open area melting thresholds ( $F$ and $G$ in Fig. 1) as well as the depth of the second and third soil layers ( $\mathrm{J}$ and $\mathrm{K}$ in Fig. 1) were particularly equifinal as the 16 behavioral sets covered the whole physical range. 


\title{
SURFACE WATER QUANTITY FOR DRINKING WATER DURING LOW FLOWS - SENSITIVITY ASSESSMENT SOLELY FROM CLIMATE DATA
}

\author{
Water Resources Management
}

Étienne Foulon ${ }^{1 *}(0000-0003-2509-6101)$, Alain N. Rousseau ${ }^{1}$ (0000-0002-3439-2124)

1 INRS-ETE/Institut National de la Recherche Scientifique-Eau Terre Environnement, 490 rue de la Couronne, Québec City, G1K 9A9, Québec, Canada

*Corresponding author: etiennefoulon59@gmail.com, 418-271-2687 

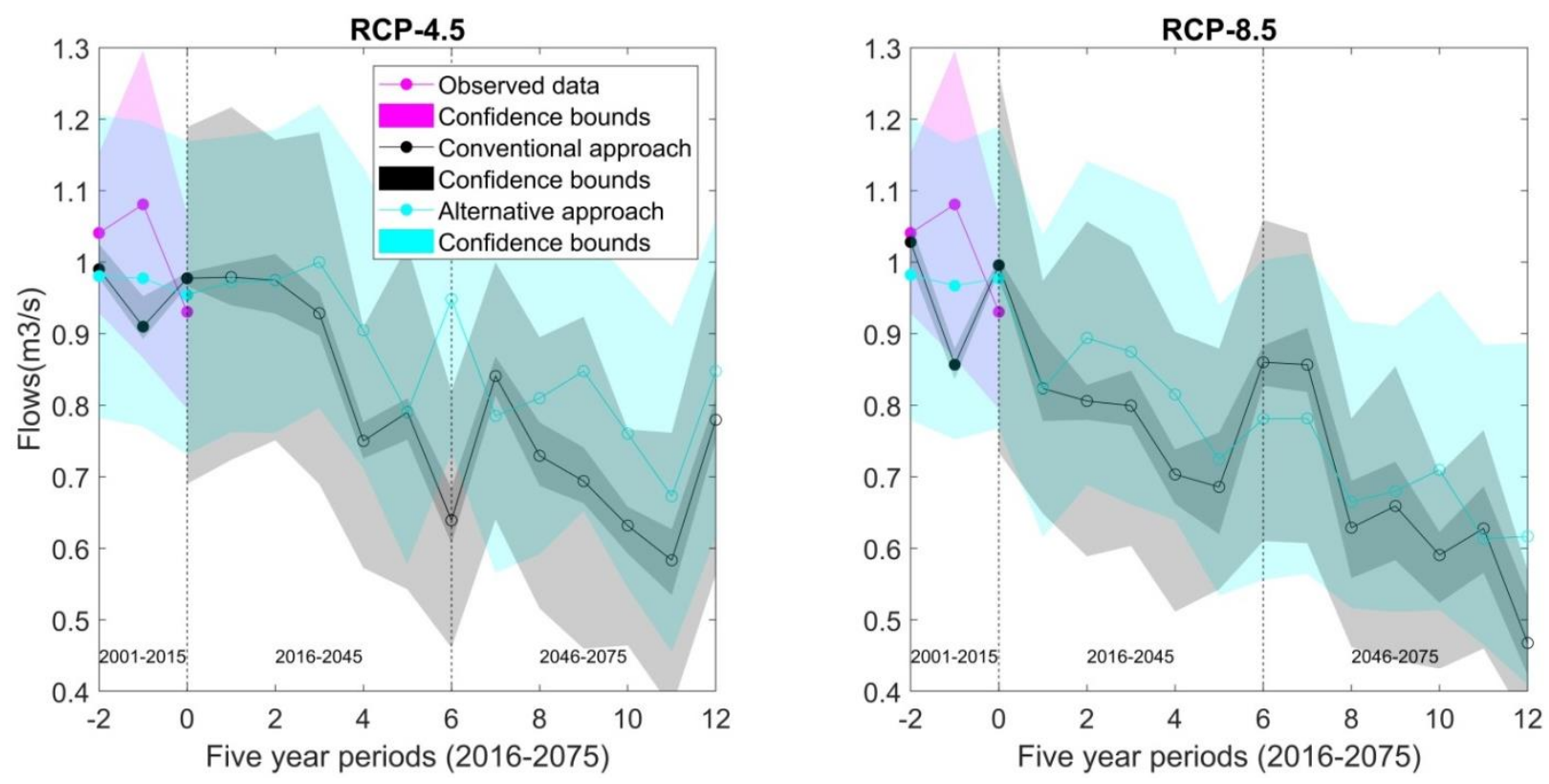

Fig. 1 Median future ${ }_{7 d} Q_{\min }$ assessed using the conventional (black) and alternative (cyan) approaches for RCP-4.5 and RCP-8.5. Confidence bounds for the conventional approach include uncertainty associated with hypothetical measurement errors as the standard deviation of averaged flows on 7 days 
The highlights for the paper are the following:

- Foulon et al. (2018)'s methodology can provide a screening assessment of future drought prone watersheds

- Assessment for RCP-4.5 and -8.5 of the low flow trends for the main water intake of Québec City

- Assessment for RCP-4.5 and -8.5 of the future pressure on water ressources for Québec City

- Testing of a methodology that may enable good water management practices for small municipalities 


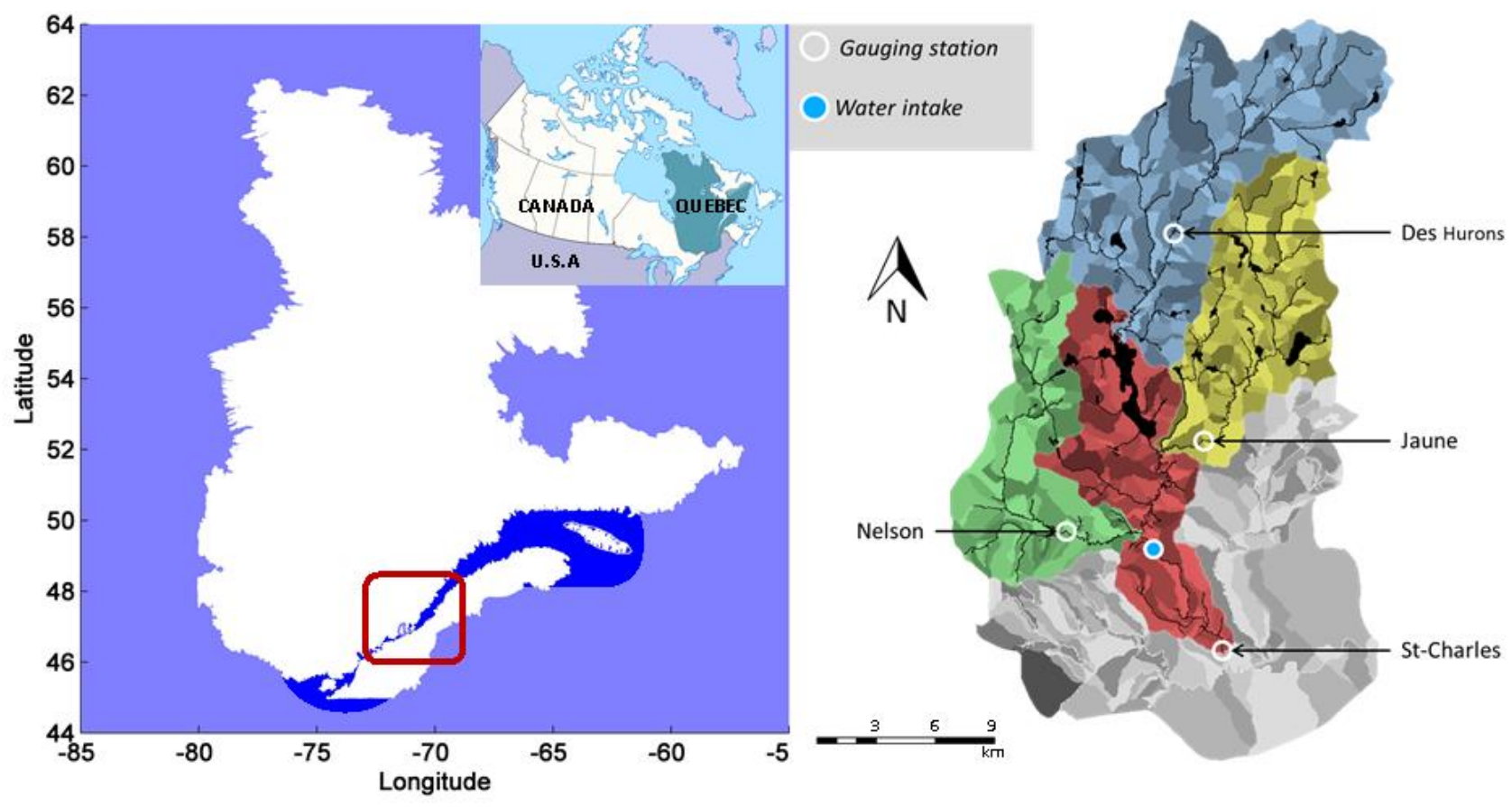




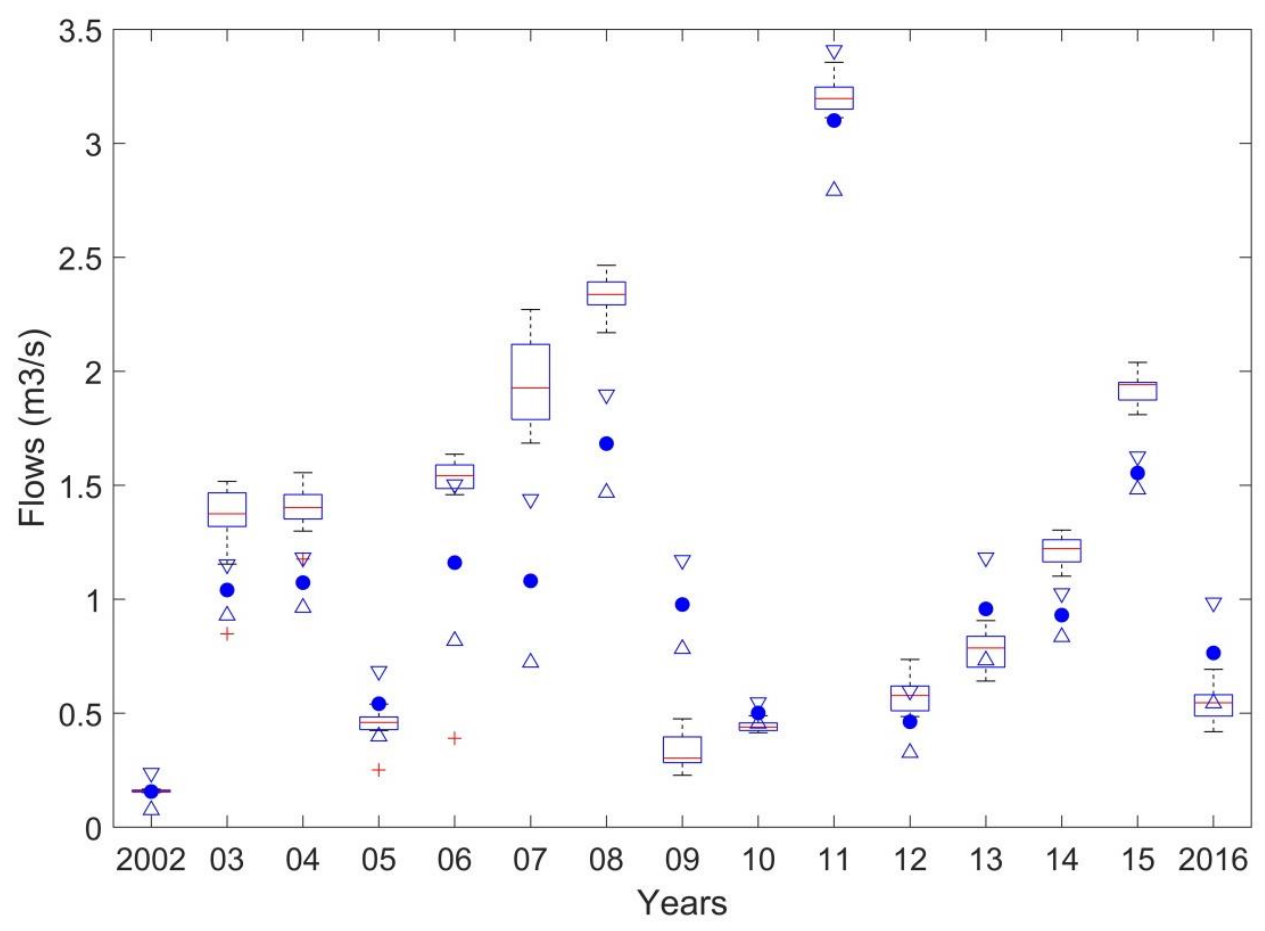




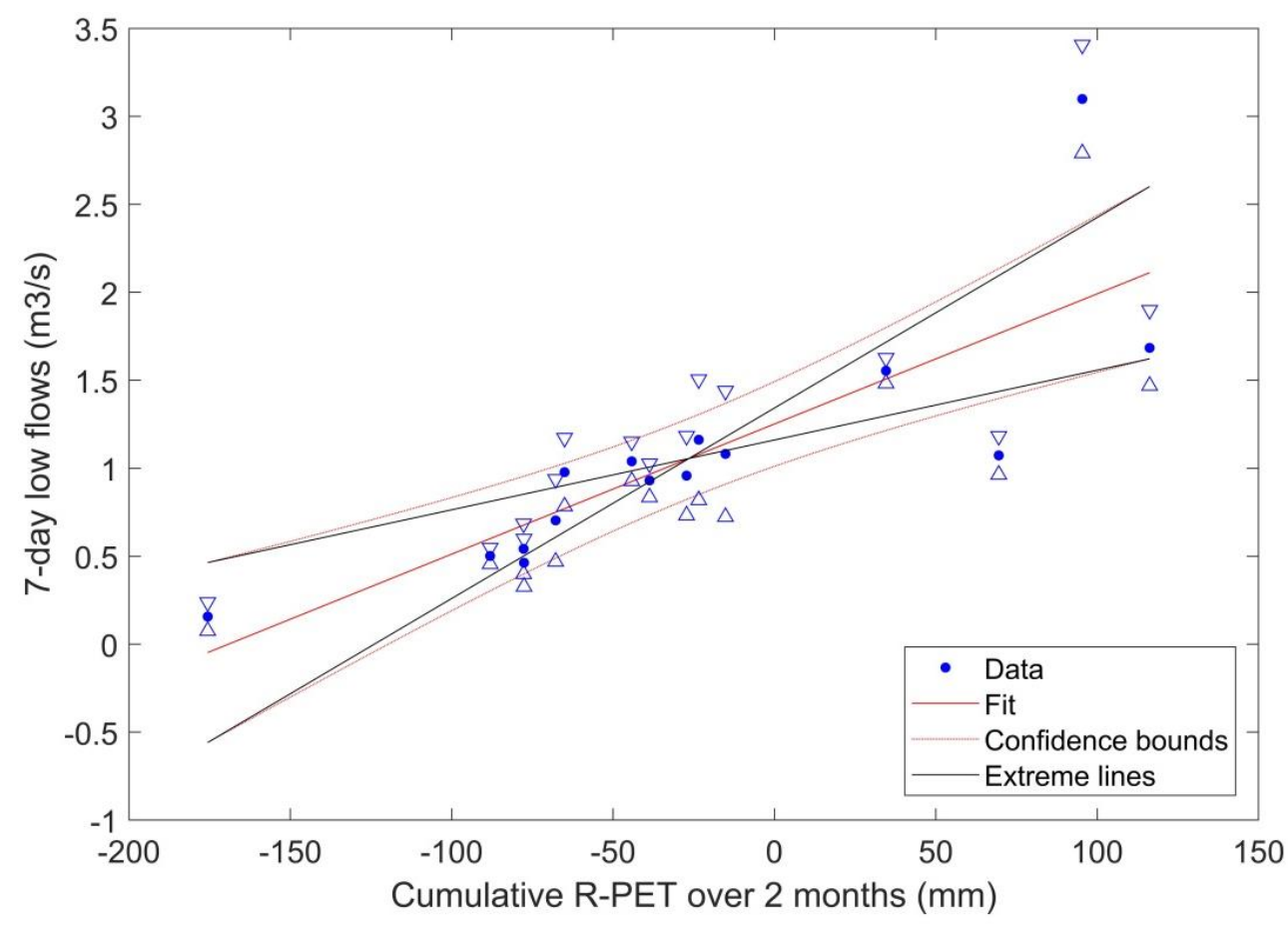



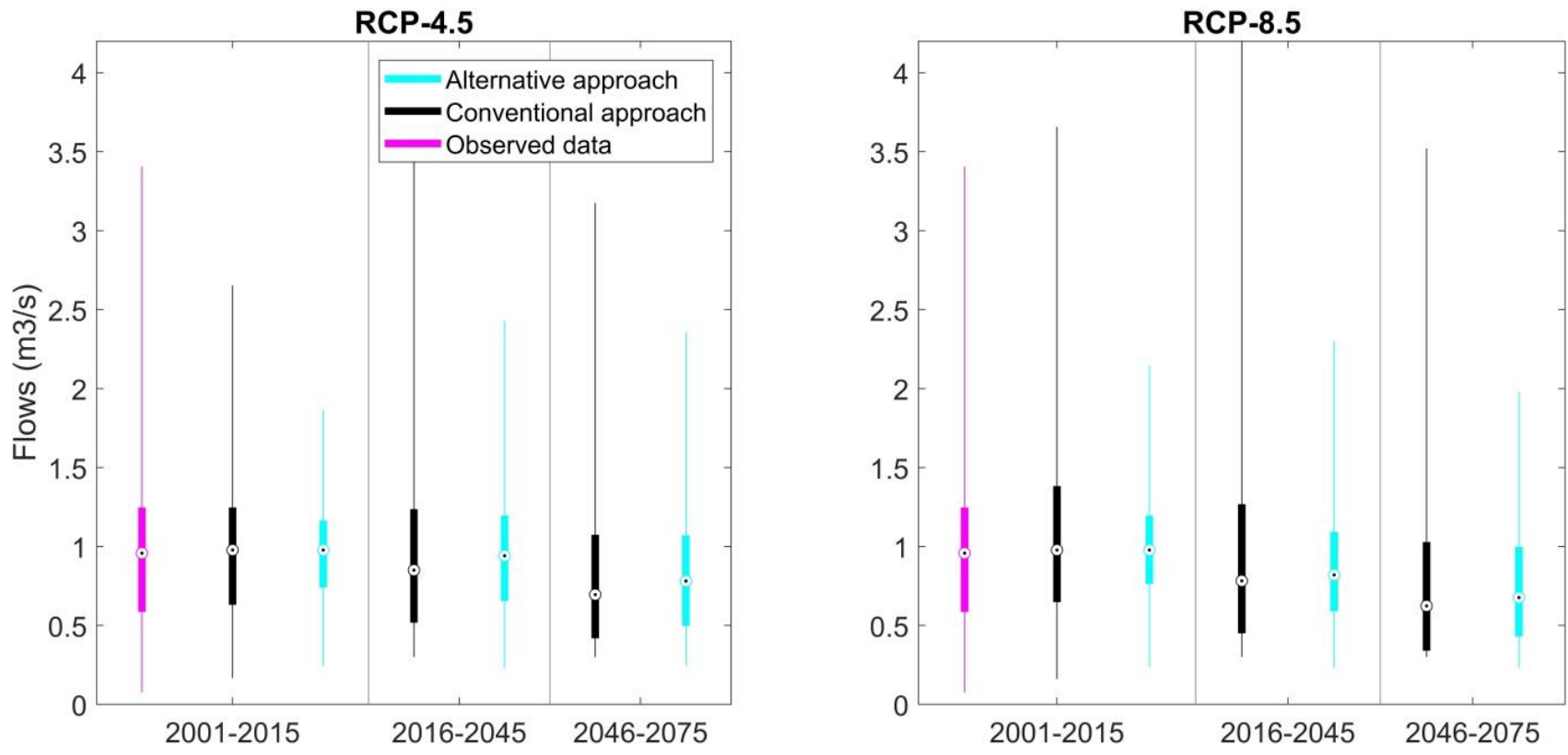

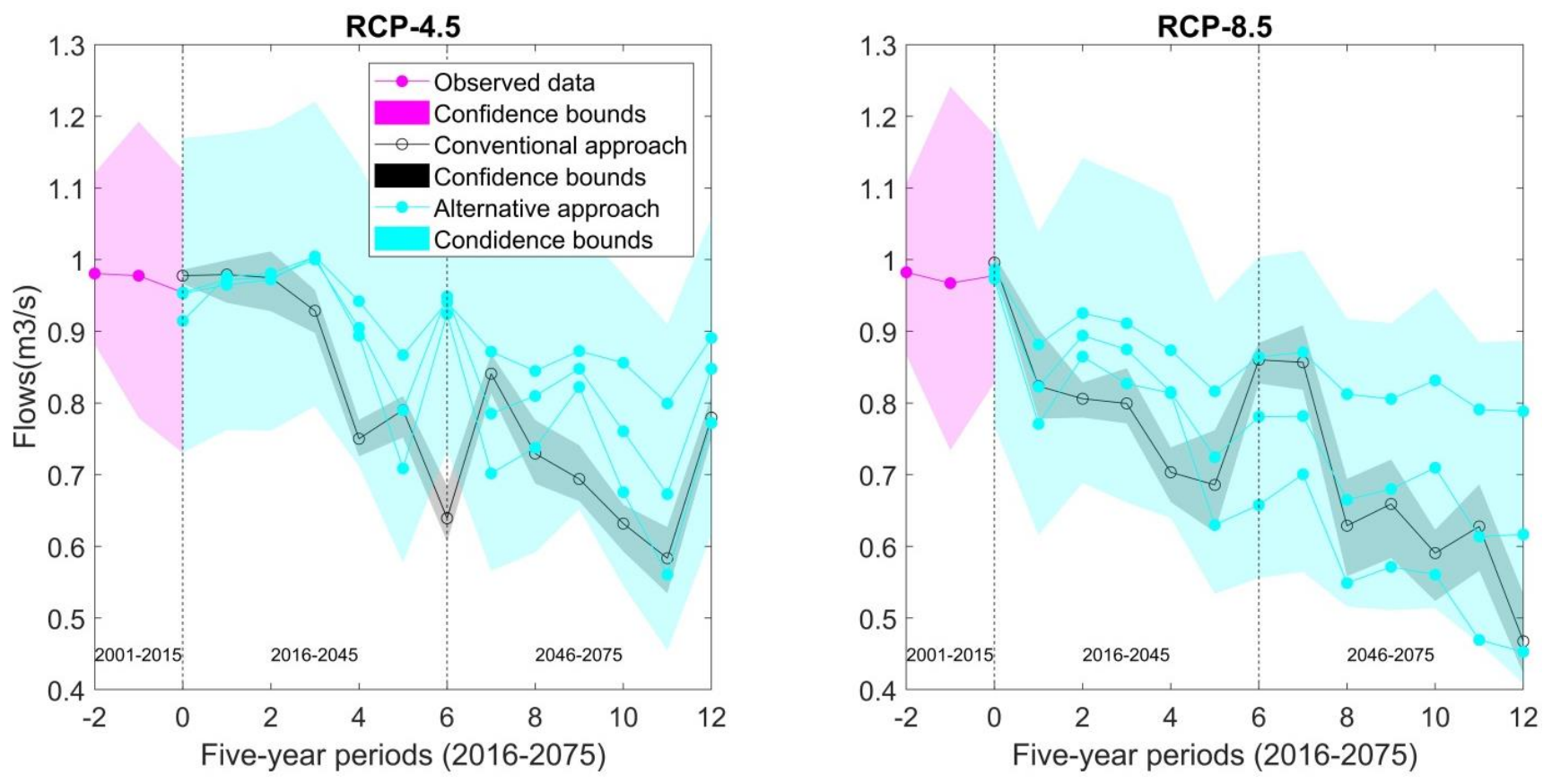